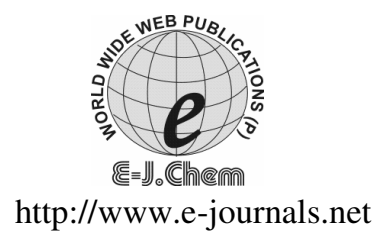

ISSN: 0973-4945; CODEN ECJHAO

E-Journal of Chemistry

Vol. 5, No.4, pp. 894-903, October 2008

\title{
Catalytic Effect of Cetyltrimethylammonium Bromide on the Oxidation of Triethylene glycol by Chloramine-T in Acidic Medium
}

\author{
VANDANA SHARMA ${ }^{\S *}$, K.V. SHARMA ${ }^{\S}$ and V. W. BHAGWAT ${ }^{\#}$ \\ ${ }^{\S}$ Department of Engg. Chemistry, \\ Mahakal Institute of Technology, Ujjain 456664, India. \\ ${ }^{\#}$ School of Studies in Chemistry, Vikram University, Ujjain 456010, India. \\ vandanak_sharma@yahoo.co.in Tel: 917344050618
}

Received 18 March 2008; Accepted 10 May 2008

\begin{abstract}
The kinetics and mechanism of cetyltrimethylammonium bromide catalyzed oxidation of triethylene glycol [2,2'-ethylene diqxybis(ethanol)] by chloramine- $\mathrm{T}$ in acidic acid medium have been investigated. The reaction is first order dependence on chloramine- $\mathrm{T}$ and fractional order for triethylene glycol with excess concentration of other reactants. The catalytic effect due to cetyletrimethylammonium bromide has been studied. The small salt effect and increase in the reaction rate with increasing dielectric constant suggest the involvement of neutral molecule in the rate-determining step. The addition of $p$-toluene sulfonamide retards the reaction rate. The effect of chloride ion on the reaction also studied. The effect of temperature on the reaction has been investigated in the temperature range $313-333 \mathrm{~K}$ and thermodynamic parameters were calculated from the Arrhenious plot. A tentative mechanism consistent with the experimental results has been proposed.
\end{abstract}

Keywords: Triethylene glycol, Chloramine-T, Cetyltrimethylammonium bromide, Oxidation, Kinetics

\section{Introduction}

Kinetics study is concerned with the rate of the reaction, the influence of various conditions on these rates and mechanisms by which a reaction occurs. The subject of chemical kinetics covers not only reaction rate but also covers a wide range of studies, which includes empirical studies of the effects of the concentrations, temperature, $\mathrm{pH}$, catalyst etc. on reactions of various types. It has proved to be the best means of study of various reactions such as oxidation, thermal decomposition, halogenation, hydrogenation etc. For large-scale production of compounds, it is very essential to know the velocity of the reaction ${ }^{1}$.

Triethylene glycol (TEG) is characterized by two hydroxyl groups along with two ether linkages, which contribute to its high water solubility, hygroscopicity, solvent properties and 
reactivity with many organic compounds. Triethylene glycol finds use as a vinyl plasticizer, as an intermediate in the manufacture of polyester resins and polyols and as a solvent in many miscellaneous applications. The main uses for TEG depend upon its hygroscopic properties. Oxidation of polyethylene glycols, different alcohols and diols by different oxidant has been carried out by various workers ${ }^{2-14}$ but no one has ever used chloramine- $\mathrm{T}$ ( $p$ - Me- $\mathrm{C}_{6} \mathrm{H}_{4}-\mathrm{SO}_{2} \mathrm{NClNa} .5 \mathrm{H}_{2} \mathrm{O}$ ) as an oxidant. Chloramine-T abbreviated as CAT, is a versatile oxidant ${ }^{15-19}$.In continuation of our work ${ }^{20-22} \mathrm{C}_{16} \mathrm{TAB}$ catalyzed oxidation of TEG by chloramine-T has been undertaken.

The oxidation of TEG by acidic chloramine-T was found an extremely slow reaction. The reaction has found to be catalyzed by a cationic surfactant cetyltrimethylammonium bromide $\left(\mathrm{C}_{16} \mathrm{TAB}\right)$.

\section{Experimental}

All the chemicals used in this investigation were of A R grade and double distilled water was used for preparation of solutions.

\section{Rate Measurements}

The kinetics and mechanism of cetyltrimethylammonium bromide catalyzed oxidation of triethylene glycol was performed titrimetrically. The unused amount of CAT was determined iodometrically ${ }^{23}$ at regular time intervals. In all the experiments, the reactions were followed up to two half lives. A constant ionic strength of the reaction mixture was maintained by adding required amount of sodium perchlorate solution.

\section{Stoichiometry}

Determination of stoichiometry is the stepping-stone for the correct approach towards the mechanistic study of any reaction. Stoichiometry was determined by using varying ratios of the oxidant to TEG were thermostatted at $25^{\circ} \mathrm{C}$ for $48 \mathrm{~h}$ incubation, and residual CAT was determined iodometrycally using standard sodium thiosulphate as titrant and potassium iodidestarch as an indicator. The mole ratio (number of moles of the chloramine-T consumed per mole of TEG) was calculated. TEG and chloramine- $\mathrm{T}$ reacts in 1:1 stoichiometry, as follows:

$$
\begin{aligned}
& \mathrm{OHCH}_{2}-\mathrm{CH}_{2}-\mathrm{O}-\mathrm{CH}_{2}-\mathrm{CH}_{2}-\mathrm{O}-\mathrm{CH}_{2}-\mathrm{CH}_{2} \mathrm{OH}+\mathrm{ArSO}_{2} \mathrm{NClNa} \rightarrow \\
& \mathrm{OHCH}_{2}-\mathrm{CH}_{2}-\mathrm{O}-\mathrm{CH}_{2}-\mathrm{CH}_{2}-\mathrm{O}-\mathrm{CH}_{2}-\mathrm{CHO}+\mathrm{ArSO}_{2} \mathrm{NH}_{2}+\mathrm{Na}^{+}+\mathrm{Cl}^{-} \\
& \text {where; } \mathrm{Ar}=\mathrm{CH}_{3} \cdot \mathrm{C}_{6} \mathrm{H}_{4}
\end{aligned}
$$

\section{Product analysis}

TEG (300 mg /250 mL water), perchloric acid (0.1 M / $100 \mathrm{~mL}), \mathrm{C}_{16}$ TAB (12 mg /100 mL) and CAT $(10 \mathrm{~g} / 100 \mathrm{~mL})$ were mixed for product analysis. After the reaction time over 48 hour, the organic components were separated from the mixture into ether; the ethereal extract was dried and concentrated using rotatory evaporator, under low pressure. Using benzene, ethyl acetate mixture 8:2 $(v / v)$ as an eluent, preliminary studies were carried out by thin layer chromatography. A distinct single spot was obtained. A solution of 2,4-DNP was added to it and then the reaction mixture was left overnight at refrigerator temperature $\left(5^{\circ} \mathrm{C}\right)$. The solution was centrifuged and brown-orange residue is obtained. This formation of hydrazine derivative adequately confirmed the oxidation product of the TEG to be a [2,2'-oxi bis(1-hydroxy)hexanal]. The aldehyde was conformed by IR spectra which shows bands at $3438 \mathrm{~cm}^{-1}$ and $1725 \mathrm{~cm}^{-1}$ for $\mathrm{OH}$ stretching and $\mathrm{C}=\mathrm{O}$ stretching respectively and a bond at $2715 \mathrm{~cm}^{-1}$ for aldehydic C-H stretching. The fact that only one hydroxyl group was attacked and other remained intact gets support from stoichiometry of the reaction as well. Literature survey shows that similar types of oxidative products were reported ${ }^{20-22,24-26}$. 


\section{Results and Discussion}

\section{The reaction order with respect to chloramine- $T$}

In a typical kinetic run, for the reaction $\left([\mathrm{CAT}]=0.004 \mathrm{~mol} \mathrm{dm}^{-3},\left[\mathrm{H}^{+}\right]=0.05 \mathrm{~mol} \mathrm{dm}^{-3}\right.$ and $\left[\right.$ TEG] $\left.=0.08 \mathrm{~mol} \mathrm{dm}^{-3}\right)$, a plot of $\log (\mathrm{a}-\mathrm{x})$ versus time (Figure 1) gave a straight line, which indicates that reaction under the chosen condition follows pseudo first order kinetics. The order with respect to CAT is unity (Table 1 ). The mean pseudo first-order rate constant, $\mathrm{k}_{0}$ found to be $(0.09 \pm 0.2) \times 10^{-5} \mathrm{~s}^{-1}$.

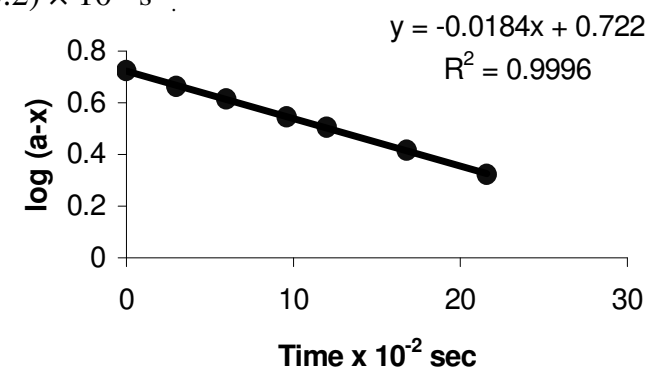

Figure 1. Plot of $\log (\mathrm{a}-\mathrm{x})$ versus time

Table 1. Order with respect to CAT

\begin{tabular}{cc}
{$[\mathrm{TEG}]=0.08$ mole dm$^{-3}$} & $\begin{array}{c}{\left[\mathrm{H}^{+}\right]=0.05 \mathrm{~mole}^{-3}} \\
\text { Temperature }=318 \mathrm{~K}\end{array}$ \\
\hline$\left[\mathrm{C}_{16} \mathrm{TAB}\right]=0.002 \mathrm{~mole}^{-3}$ & $* \mathrm{k} / 10^{-4} \mathrm{~s}^{-1}$ \\
\hline$[\mathrm{CAT}] / 10^{-3} \mathrm{~mol} \mathrm{dm}^{-3}$ & 8.48 \\
0.5 & 5.39 \\
1.0 & 4.26 \\
2.0 & 3.62 \\
3.0 & 2.76 \\
4.0 & 1.31 \\
6.0 & 0.78 \\
8.0 &
\end{tabular}

A slight fall in rate constants with increasing [CAT] may be explained on the basis of some deactivation caused by traces of inactive sodium chlorate formed in a side reaction as shown ${ }^{27}$ in equation (2).

$$
3 \mathrm{NaOCl} \rightarrow \mathrm{NaClO}_{3}+2 \mathrm{NaCl}
$$

\section{The reaction order with respect to [TEG]}

On varying TEG concentration from 0.02 to $0.24 \mathrm{~mol} \mathrm{dm}^{-3}$, there is an increase in rate of reaction. The plots of $\log \mathrm{k}$ versus $\log$ [TEG] (Figure 2) gave straight line with slop equal to $0.57\left(\mathrm{R}^{2}=0.99\right)$, suggesting that order with respect to TEG is fractional. A double reciprocal plot between $\mathrm{k}^{-1}$ versus $\left[\right.$ TEG] ${ }^{-1}$ (Figure 3 ) has been found to be straight line with positive intercept at $y$-axis. This kinetic evidence of complex formation between the substrate and the oxidant, further support the fractional order dependence.

The effect of variation of hydrogen ion

On varying perchloric acid concentration from 0.025 to $0.200 \mathrm{~mol} \mathrm{dm}^{-3}$ there is an increase in reaction rate was observed. The plots of $\log \mathrm{k}$ versus $\log \left[\mathrm{H}^{+}\right]$(Figure 6) gave straight line with positive intercept $0.17\left(\mathrm{R}^{2}=0.95\right)$, suggesting that acid plays a complex role in the reaction system. The cause of the increase in the reaction rate with the increasing acid concentration may be attributed to the following equlibria ${ }^{28}$. 


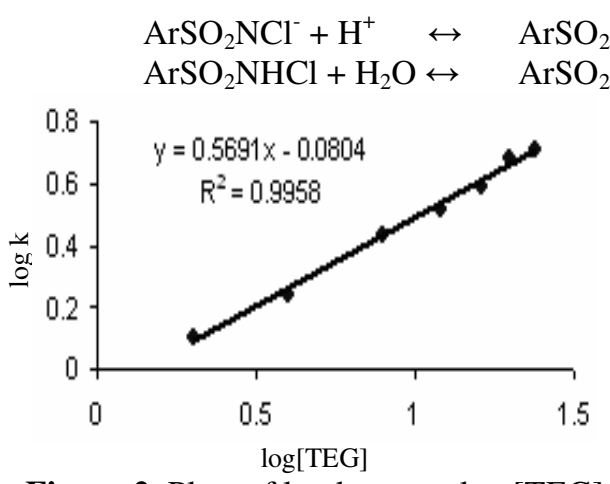

Figure 2. Plots of log k versus log [TEG]

Table 2. Effect of triethylene glycol concentration variation

\begin{tabular}{cc}
{$[\mathrm{CAT}]=0.004 \mathrm{~mole} \mathrm{dm}^{-3}$} & $\begin{array}{c}{\left[\mathrm{H}^{+}\right]=0.05 \mathrm{~mole}^{-3}} \\
\text { Temperature }=318 \mathrm{~K}\end{array}$ \\
\hline $\left.\mathrm{C}_{16} \mathrm{TAB}\right]=0.002 \mathrm{~mole}^{-3}$ & $* \mathrm{k} / 10^{-4} \mathrm{~s}^{-1}$ \\
\hline TEG] $/ 10^{-2} \mathrm{~mol} \mathrm{dm}^{-3}$ & 1.29 \\
4.0 & 1.50 \\
8.0 & 2.74 \\
12.0 & 3.32 \\
16.0 & 3.62 \\
20.0 & 4.74 \\
24.0 & 5.53
\end{tabular}

It is evident from the above reaction; that an increase in the acid concentration results in the formation of more $\mathrm{HOCl}$, consequently the reaction rate increases.

Table 3. Effect of hydrogen ion concentration variation

$$
\begin{array}{ll}
{[\mathrm{TEG}]=0.08 \mathrm{~mole} \mathrm{dm}^{-3}} & {[\mathrm{CAT}]=0.004 \mathrm{~mole} \mathrm{dm}^{-3}} \\
{\left[\mathrm{C}_{16} \mathrm{TAB}\right]=0.002 \mathrm{~mole} \mathrm{dm}^{-3}} & \text { Temperature }=318 \mathrm{~K}
\end{array}
$$

\begin{tabular}{cc}
\hline$\left[\mathrm{HClO}_{4}\right] / 10^{-2} \mathrm{~mol} \mathrm{dm}^{-3}$ & $\mathrm{k} / 10^{-4} \mathrm{~s}^{-1} *$ \\
\hline 1.25 & 2.12 \\
2.50 & 2.53 \\
5.00 & 2.83 \\
10.00 & 2.90 \\
20.00 & 3.66 \\
40.00 & 3.92 \\
\hline
\end{tabular}

* Mean of duplicate experiments

Dependence of rate on $\left[C_{16} T A B\right]$

The addition of $\mathrm{C}_{16} \mathrm{TAB}$ in the reaction system catalyzed the reaction. The reaction rate increase with the increase in concentration of $\mathrm{C}_{16} \mathrm{TAB}$ from 0.002 to $0.010 \mathrm{~mol} \mathrm{dm}^{-3}$. The plot of $\mathrm{k}$ versus $\left[\mathrm{C}_{16} \mathrm{TAB}\right]$ (Figure 5) gives a straight line. Surfactants are tending to form micelles. The reported critical miceller concentration of $\mathrm{C}_{16} \mathrm{TAB}$ is $9.2 \times 10^{-4}$ at $25^{\circ} \mathrm{C}$. One of the important properties of miceller systems is their ability to affect the rates of chemical reactions. The reaction rate can either be accelerated or retarded, depending on chemical system, the type and concentration of 
surfactant and other factors such as $\mathrm{pH}$, ionic strength etc. The effect of surfactants on reaction kinetics is called miceller catalysis ${ }^{29}$. Micelles are formed due to assembling of amphiphilic molecules of surfactant in above a certain concentration called as critical miceller concentration ${ }^{30,31}$. Miceller catalysis of reaction in aqueous solutions is usually explained on the basis of a distribution of reactants between water and the miceller 'pseudo phase'. The micelles may provide a favorable orientation of the reactants by polarity gradients. In present case hydrophobic interaction is most likely to be operative due to relative larger hydrocarbon chains of the substrate ${ }^{32,33}$. This interactive localization of the reacting species in the relatively small volume of the micelles compared to the bulk solution leads to a large increase in the effective concentration and as a result the observed rate increased accordingly. The other most probable reason seems to be electrostatic attraction between polar TEG molecule and the micelle.

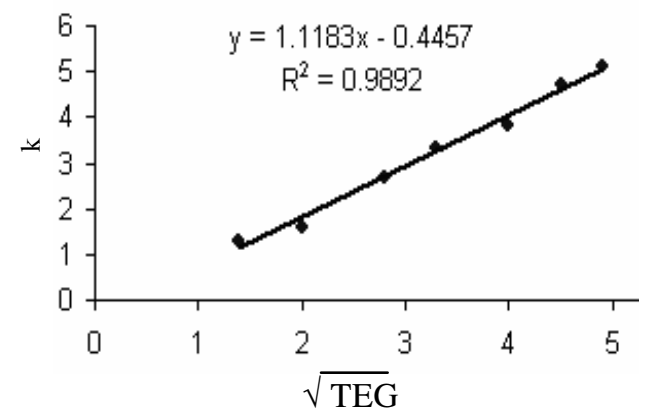

Figure 4. Plot between $k$ and $\sqrt{[\text { TEG }]}$

Table 4. Effect of $\mathrm{C}_{16} \mathrm{TAB}$ concentration variation

\begin{tabular}{cc}
{$[\mathrm{TEG}]=0.08 \mathrm{~mole} \mathrm{dm}^{-3}$} & $\begin{array}{c}{[\mathrm{CAT}]=0.004 \text { mole } \mathrm{dm}^{-3}} \\
\text { Temperature }=318 \mathrm{~K}\end{array}$ \\
\hline$\left[\mathrm{HClO}_{4}\right]=0.05 \mathrm{~mole} \mathrm{dm}^{-3}$ & $* \mathrm{k} / 10^{-4} \mathrm{~s}^{-1}$ \\
\hline$\left[\mathrm{C}_{16} \mathrm{TAB}\right] / 10^{-3} \mathrm{~mol} \mathrm{dm}^{-3}$ & 0.022 \\
2.0 & 2.10 \\
3.0 & 2.76 \\
4.0 & 2.70 \\
6.0 & 3.16 \\
8.0 & 3.94 \\
10.0 & 4.64 \\
\hline
\end{tabular}

* Mean of duplicate experiments

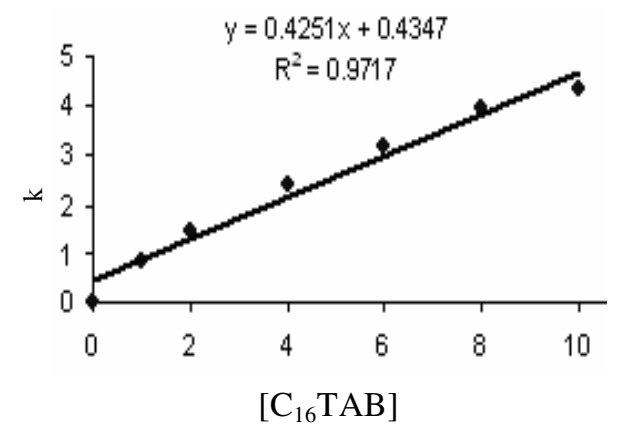

Figure 5. Plot of $\mathrm{k}$ versus $\left[\mathrm{C}_{16} \mathrm{TAB}\right]$

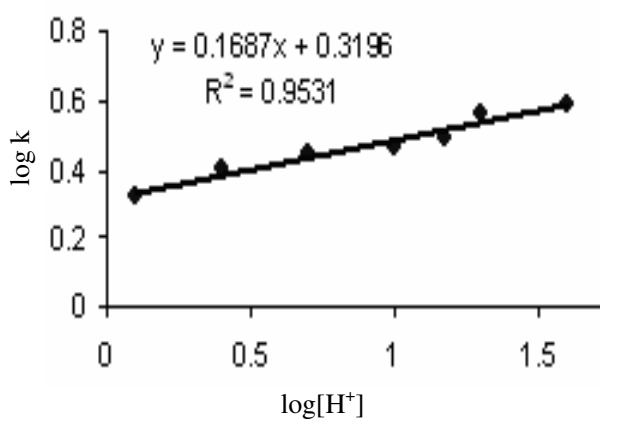

Figure 6. Plot of $\log \mathrm{k}$ versus $\log \left[\mathrm{H}^{+}\right]$ 


\section{Effect of variation of the [Cl]}

The role of chloride ion in the kinetics and mechanism of the oxidation reaction by CAT is very crucial. On varying chloride ion concentration from 0.002 to $0.080 \mathrm{~mol} \mathrm{dm}^{-3}$, the rate of reaction increases. The plot of $\log \mathrm{k}$ versus $\log \left[\mathrm{Cl}^{-}\right]$(Figure 7) is a straight line with a slope of $0.15\left(\mathrm{R}^{2}=0.97\right)$. The cause of acceleration in the reaction rate is the generation of molecular chlorine $/ \mathrm{HOCl}$ due to the interaction between a chloride ion and a chloronium ion produced by the hydrolysis of $\mathrm{N}-\mathrm{Cl}$ bond, in polar medium. Alternatively, the added chloride ion may coordinate with the protonated oxidant to give rise to species of the type (I).

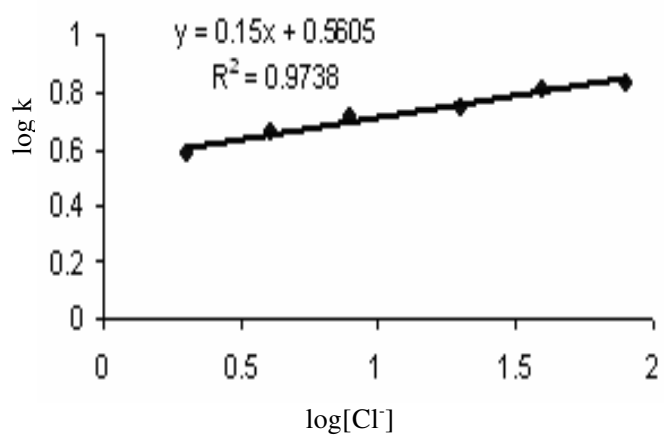

Figure 7. Plot of $\log \mathrm{k}$ versus $\log \left[\mathrm{Cl}^{-}\right]$

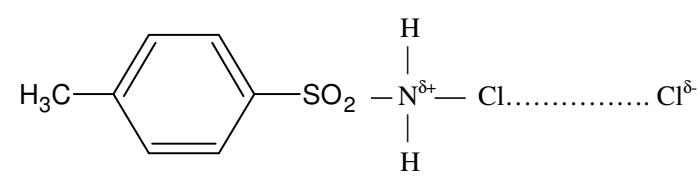

Type (I)

Effect of variation of the ionic strength, dielectric constant and addition of p-toluenesulphonamide (PTS)

With the employed reactant concentrations, initial ionic strength of the reaction mixture was 0.058. It was found that there is no substantial change in the reaction rate on varying the ionic strength from 0.058 to 0.118 by the addition of neutral sodium perchlorate. The small salt effect suggests the participation of neutral species in rate determining step i.e. the substrate molecule and $\mathrm{HOCl}$. This assumption further got support from effect of change in dielectric constant of the reaction medium. The effect of dielectric constant in reaction medium has been studied by adding acetic acid (40$60 \%$ ) in the reaction medium at constant concentrations of other reactants. The rate of reaction increases by increasing the proportion of acetic acid in solvent medium; this supports the involvement of neutral species in the rate-determining step. Addition of PTS, one of the reaction products, from 0.0005 to $0.008 \mathrm{~mol} \mathrm{dm}^{-3}$ at constant CAT and TEG concentration, decreases the rate of reaction. This supports that $\mathrm{HOCl}$ is the main oxidizing species.

$$
\mathrm{ArSO}_{2} \mathrm{NHCl}+\mathrm{H}_{2} \mathrm{O} \leftrightarrow \mathrm{ArSO}_{2} \mathrm{NH}_{2}+\mathrm{HOCl}
$$




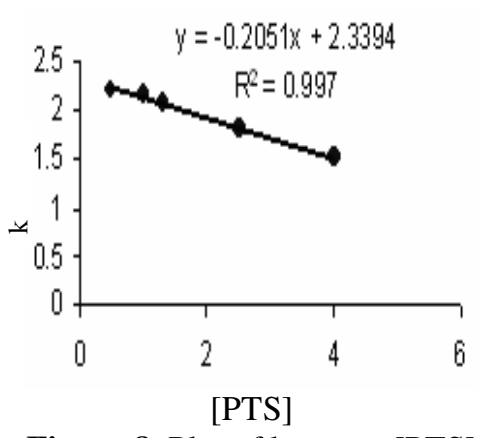

Figure 8. Plot of k versus [PTS]

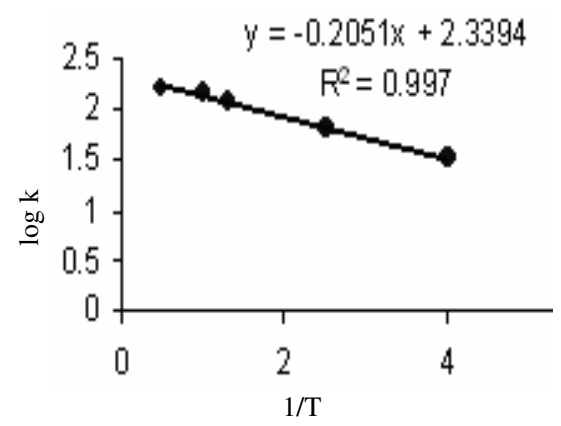

Figure 9. Arrhenius plot

\section{Effect of temperature}

By increasing temperature the rate of the reaction increases, $\log \mathrm{k} v s 1 / \mathrm{T}$ (Figure 9) is a straight line in the temperature range 313-333 K. This shows Arrhenius equation is valid for this reaction. From the linear Arrhenius plot activation parameters for overall reaction were evaluated $\mathrm{Ea}=63.35 \mathrm{KJ} \mathrm{mol}^{-1} \Delta \mathrm{H}^{*}=60.70 \mathrm{KJ} \mathrm{mol}^{-1}, \Delta \mathrm{G}^{*}=72.74 \mathrm{KJ} \mathrm{mol}^{-1}, \Delta \mathrm{S}^{*}=-32.84 \mathrm{JK}$ $\mathrm{mol}^{-1}$ respectively.

\section{Mechanism}

Chloramine- $\mathrm{T}$ is a strong electrolyte ${ }^{28}$ and in aqueous solution it behaves as follows:

$$
\mathrm{ArSO}_{2} \mathrm{NNaCl} \leftrightarrow \mathrm{ArSO}_{2} \mathrm{NCl}^{-}+\mathrm{Na}^{+} \mathrm{N}
$$

The anion $\mathrm{ArSO}_{2} \mathrm{NCl}^{-}$is protonated in acidic solutions to give $N$-chlorotoluene- $p$ sulphonamide.

$$
\mathrm{ArSO}_{2} \mathrm{NCl}^{-}+\mathrm{H}^{+} \leftrightarrow \mathrm{ArSO}_{2} \mathrm{NHCl}
$$

This $\mathrm{ArSO}_{2} \mathrm{NHCl}$ undergoes hydrolysis according to the following reactions:

$$
\begin{aligned}
2 \mathrm{ArSO}_{2} \mathrm{NHCl} & \leftrightarrow \mathrm{ArSO}_{2} \mathrm{NCl}_{2}+\mathrm{ArSO}_{2} \mathrm{NH}_{2} \\
\mathrm{ArSO}_{2} \mathrm{NCl}_{2}+\mathrm{H}_{2} \mathrm{O} & \leftrightarrow \mathrm{ArSO}_{2} \mathrm{NHCl}_{2}+\mathrm{HOCl} \\
\mathrm{ArSO}_{2} \mathrm{NHCl}+\mathrm{H}_{2} \mathrm{O} & \leftrightarrow \mathrm{ArSO}_{2} \mathrm{NH}_{2}+\mathrm{HOCl}
\end{aligned}
$$

In weakly acidic media $(\mathrm{pH}=6-7), \mathrm{ArSO}_{2} \mathrm{NHCl}$ is the prominent reacting species of CAT while at higher acid concentrations $(\mathrm{pH}<2.8) \quad \mathrm{ArSO}_{2} \mathrm{NHCl}$ is further protonated according to equation (11).

$$
\mathrm{ArSO}_{2} \mathrm{NHCl}+\mathrm{H}^{+} \leftrightarrow \mathrm{ArSO}_{2} \mathrm{NH}_{2} \mathrm{Cl}^{+}
$$

Thus, the possible oxidizing species in acidic solutions of CAT are $\mathrm{ArSO}_{2} \mathrm{NH}_{2} \mathrm{Cl}$, $\mathrm{ArSO}_{2} \mathrm{NHCl}, \mathrm{ArSO}_{2} \mathrm{NCl}_{2}$ (dichloramine-T) and $\mathrm{HOCl}$. It was found that the reaction rate is retarded on addition of PTS. This is indicative of the fact that either $\mathrm{ArSO}_{2} \mathrm{NCl}_{2}$ or $\mathrm{HOCl}$ could be the main oxidizing species. To account for the experimental observations, the following mechanism proposed. The linear double reciprocal plot with intercept on y-axis of $\mathrm{k}^{-1}$ vs $[\mathrm{TEG}]^{-1}$ suggests the formation of complex between the substrate and the oxidant.

Thus the rate determining step proposed is:

$$
\begin{aligned}
& \mathrm{OHCH}_{2}-\mathrm{CH}_{2}-\mathrm{O}-\mathrm{CH}_{2}-\mathrm{CH}_{2}-\mathrm{O}-\mathrm{CH}_{2}-\mathrm{CH}_{2} \mathrm{OH}+\mathrm{HOCl} \stackrel{\text { Slow }}{\longrightarrow} \mathrm{X}_{1} \\
& \mathrm{X}_{1}+\mathrm{H}_{2} \mathrm{O} \stackrel{\text { Fast }}{\longrightarrow} \mathrm{OHCH}_{2}-\mathrm{CH}_{2}-\mathrm{O}-\mathrm{CH}_{2}-\mathrm{CH}_{2}-\mathrm{O}-\mathrm{CH}_{2}-\mathrm{CHO}+2 \mathrm{H}_{2} \mathrm{O}+\mathrm{HCl}
\end{aligned}
$$


The small salt effect, increase in reaction rate on increasing the dielectric constant and straight line double reciprocal plots between $1 / \mathrm{k}$ versus $1 /$ [TEG] with positive intercept at $y$-axis (Figure 3), support equation (12) as being the rate determining step. The thus formed complex decomposes quickly into the products, equation (13).

\section{Mechanism in the presence of chloride ions}

On increasing concentration of chloride ions, the reaction rate increases. The order with respect to chloride ions is fractional. The increase in the reaction rate in the presence of chloride ions may be attributed to the following reactions:

$$
\begin{aligned}
\mathrm{ArSO}_{2} \mathrm{NHCl}+\mathrm{Cl}^{-} & \leftrightarrow \mathrm{ArSO}_{2} \mathrm{NH} \ldots \ldots \ldots \ldots . . . \mathrm{Cl}^{-} \\
\mathrm{ArSO}_{2} \mathrm{NH} \ldots . . \mathrm{Cl}^{-} & \leftrightarrow \mathrm{ArSO}_{2} \mathrm{NH}^{-}+\mathrm{Cl}_{2} \\
\mathrm{Cl}_{2}+\mathrm{H}_{2} \mathrm{O} & \leftrightarrow \mathrm{HOCl}+\mathrm{HCl}
\end{aligned}
$$

Thus, the $\mathrm{HOCl}$ generated in equation (16) commences oxidizing the substrate simultaneously in a parallel reaction to that in equation (12) and (13).

\section{$C_{16} T A B$ catalyzed mechanism}

The reaction between the TEG and chloramine- $\mathrm{T}$ is extremely slow. The addition of $\mathrm{C}_{16} \mathrm{TAB}$ accelerates the reaction substantially. The physical basis for micelle catalysis involves several contributing factors. First there is the effect of the micelle environment on the ratecontrolling step in the reaction mechanism. The relative free energies of the reactions and /or the transition state can be altered when the reaction occurs in the micelle phase instead of bulk water. This concept is reminiscent of enzymatic catalysis and many initial studies of micelle systems focused on this possibility. More important consideration is the interactive localization of reacting species in the relatively small volume of the micelle compared to that of the bulk solution. This leads to a large increase in the effectively concentration and the observed rate (in terms of moles per unit time per liter of the entire solution) increases accordingly. The following mechanism is envisioned for the catalysis by $\mathrm{C}_{16} \mathrm{TAB}$ :

$$
\begin{aligned}
& \mathrm{nC}_{16} \mathrm{TAB} \rightarrow\left(\mathrm{C}_{16} \mathrm{TAB}\right)_{\mathrm{n}} \\
& \mathrm{OHCH}_{2}-\mathrm{CH}_{2}-\mathrm{O}-\mathrm{CH}_{2}-\mathrm{CH}_{2}-\mathrm{O}-\mathrm{CH}_{2}-\mathrm{CH}_{2} \mathrm{OH}+\left(\mathrm{C}_{16} \mathrm{TAB}\right)_{\mathrm{n}} \rightarrow \\
& {\left[\mathrm{OHCH}_{2}-\mathrm{CH}_{2}-\mathrm{O}-\mathrm{CH}_{2}-\mathrm{CH}_{2}-\mathrm{O}-\mathrm{CH}_{2}-\mathrm{CH}_{2} \mathrm{OH} \ldots .\left(\mathrm{C}_{16} \mathrm{TAB}\right)_{n}\right]} \\
& {\left[\mathrm{OHCH}_{2}-\mathrm{CH}_{2}-\mathrm{O}-\mathrm{CH}_{2}-\mathrm{CH}_{2}-\mathrm{O}-\mathrm{CH}_{2}-\mathrm{CH}_{2} \mathrm{OH} \ldots .\left(\mathrm{C}_{16} \mathrm{TAB}\right)_{\mathrm{n}}\right]+\mathrm{HOCl} \rightarrow \mathrm{X}_{1}} \\
& \mathrm{X}_{1}+\mathrm{H}_{2} \mathrm{O} \rightarrow \mathrm{OHCH}_{2}-\mathrm{CH}_{2}-\mathrm{O}-\mathrm{CH}_{2}-\mathrm{CH}_{2}-\mathrm{O}-\mathrm{CH}_{2}-\mathrm{CHO}+2 \mathrm{H}_{2} \mathrm{O}+\mathrm{HCl}
\end{aligned}
$$

Rate law

The rate equation for the reaction between TEG and CAT can be represented by the equation -

$$
-\mathrm{d}[\mathrm{CAT}] / \mathrm{dt}=\mathrm{k}_{0}[\mathrm{TEG}]^{1 / 2}[\mathrm{NCSA}]
$$

When $[\mathrm{CAT}]$ in excess above equation (21) reduces to

$$
\mathrm{r}=\mathrm{k}_{0}^{\prime}[\mathrm{TEG}]^{1 / 2}
$$

Where the rate constant for catalyzed reaction, $\mathrm{k}_{0}^{\prime}=\mathrm{k}_{0}$ [CAT]. The plot between $\mathrm{k}$ and

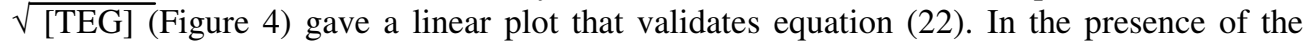
catalyst, the oxidation proceeds through catalyzed pathways. Therefore, the following represents the rate of depletion of CAT in presence of catalyst under excess [TEG] and acid concentrations:

$$
\begin{aligned}
-\mathrm{d}[\mathrm{CAT}] / \mathrm{dt}=\left\{\mathrm{k}_{0}^{\prime}+\mathrm{k}_{\mathrm{c}}^{\prime}\left[\mathrm{C}_{16} \mathrm{TAB}\right]\right\}[\mathrm{CAT}] \\
\text { where } \mathrm{k}_{\mathrm{c}}^{\prime}=\mathrm{k}_{\mathrm{c}}[\mathrm{CAT}] \\
=\mathrm{k}^{\prime \prime}[\mathrm{CAT}] \text { where } \mathrm{k}^{\prime \prime}=\left\{\mathrm{k}_{0}^{\prime}+\mathrm{k}_{\mathrm{c}}^{\prime}\left[\mathrm{C}_{16} \mathrm{TAB}\right]\right\}
\end{aligned}
$$


Equation (24) holds well, when a plot of the observed rate constant in presence of catalyst, $k$ versus $\left[\mathrm{C}_{16} \mathrm{TAB}\right]$ is linear (Figure 5).

\section{Conclusions}

The following conclusions can be drawn from the present work under the observed test conditions:

- The oxidation of the TEG by acidic chloramine-T was found an extremely slow reaction. The reaction has found to be catalyzed by a cationic surfactant cetyltrimethylammonium bromide $\left(\mathrm{C}_{16} \mathrm{TAB}\right)$.

- The stoichiometry of the reaction between TEG and CAT is 1:1.

- The order with respect to TEG is fractional and for CAT is one.

- The reaction shows increase in rate when hydrogen ion concentration increases.

- The reaction shows positive chloride ion effect.

- The reaction shows positive temperature effect and it obeys Arrhenius relationship.

- On the basis of product analysis it is proposed that on oxidation, triethylene glycol [2, 2'-ethylene diqxybis (ethanol)] oxidizes in to corresponding aldehyde i.e. [2,2'oxibis(1-hydroxy)hexanal].

\section{References}

1. Wood C W and Holliday A K, Physical Chemistry, $3^{\text {rd }}$ Ed., English Language Book Society and Butterworths, London, 1973.

2. Marcelo N, Wagner F De G and Jose R. R, J Mol Catal A: Chemical 1998, 135(3), 249.

3. Hirano M, Kojima K, Yakabe S and Morimato T, J Chem Res., 2001, 2001(7), 274.

4. Joseph J K, Jain S L and Sen B, European J Org Chem., 2006, 3, 590.

5. Konyukhov V Yu, Chernaa I V and Naumov V A, Kinet Catal., (Transl Kinet Katal.), 1997, 38, 811.

6. Benjankiwar R S, Basu A and Cementi M, J Environ Sci., (China), 2004, 16(5), 851.

7. Mantzavinos D, Hillenbrand R, Livingston A G and Metcalfs I S, Appl Catal., B; Environ, 1996, 11(1), 99.

8. Singh R A, and Singh R S, Oxid Commun., 1997, 20, 248.

9. Tandon M and Krishna P K, Z. Phys Chem., (Leipzig), 1985, 266, 1153.

10. Goswami G, Kothari S and Banerji K K, Proc Indian Acad Sci., 2001, 113(1), 43.

11. Gosain J and Sharma P K, Proc Indian Acad Sci., 2003, 115(2), 135.

12. Behari K, Shrivastava R and Veena, J Chem Res., 2001, 2001(5), 182.

13. Svetlakov N V, Nikitin V G and Orekhova A O, Russian J Org Chem.,, 2002, 38(5), 753.

14. Jin-Huan S, Shu-Ying H, Fei-Wang, Shi-Gang S and Han-Wen S, J. Chem. Res., 2004, 2004,(10), 674.

15. Puttaswamy, Jagadeesh R V, Int J Chem Kinet., , 2005, 37(4), 201.

16. Grover N, Kambo N and Upadhyay S K, Int J Chem Kinet ., 2002, 34(10), 603.

17. Lakshminarayana V, J Agric Food Chem., 1976, 24(5), 1035.

18. Anraku M, Kragh-Hasaen U, Kawai K, Maruyama T, Yamasaki Y, Takakura Y and Otagiri M, Pharm Res.,, 2003, 20(4), 684.

19. Pandey E, Grover N, Kambo N and Upadhyay S K, Indian J Chem., 2004, 43A, 1186.

20. Sharma Vandana, Sharma K V and Bhagwat V W, PCAIJ, 2007, 2(4), 260.

21. Sharma Vandana, Sharma K V and Bhagwat V W, E J Chem., 2008, 5(3), 598-606.

22. Sharma Vandana, Sharma K V and Bhagwat V W, PCAIJ, 2008, 3(1), 67.

23. Vogel I A, Text book of Quantitative Inorganic analysis, $4^{\text {th }}$ Ed. ELBS, 1986.

24. Gupta C, Mishra S K and Sharma P D, Trans Met Chem., 1994, 19, 6569. 
25. Bhagwat V W, Tiwari J, Choube A and Pare B, J Serb Chem Soc., 2003, 68(7), 535.

26. Kawai H, Kimura F, Fukaya T, Tani M, Ogata Y, Ueno K and Fukami T, Appl Environ Microbiol., 1978, 35(4), 679.

27. Sing B, Samant A K and Saxena B B L, Proc Indian Natl Sci Acad., 1983, 49A, 5.

28. Agrawal M C and Upadhyay S K J, J Sci Ind Res., 1990, 49,13.

29. Fendler J H, "Membrane Mimetic Chemistry", John Wiley New York, 1982, Chapter 2-6.

30. Wennerstrom H and Lindman B, Phys Rev., 1979, 52, 1.

31. Mukherjee P, Adv Colloid Interface Sci., 1967, 1, 241.

32. Fisher L R and Oakenfull D G, Quart Rev Chem Soc., 1977, 6, 25.

33. Bacchawat J M, Koul A K, Prasad B and Ramegowda N S, Indian J Chem., 1973, 11, 609 . 


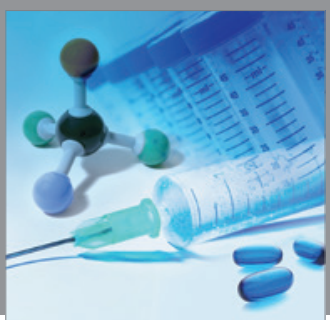

International Journal of

Medicinal Chemistry

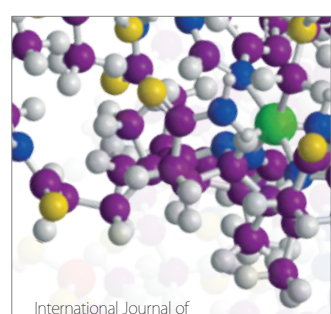

Carbohydrate Chemistry

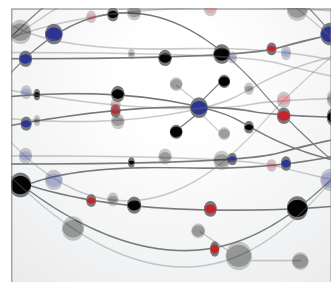

The Scientific World Journal
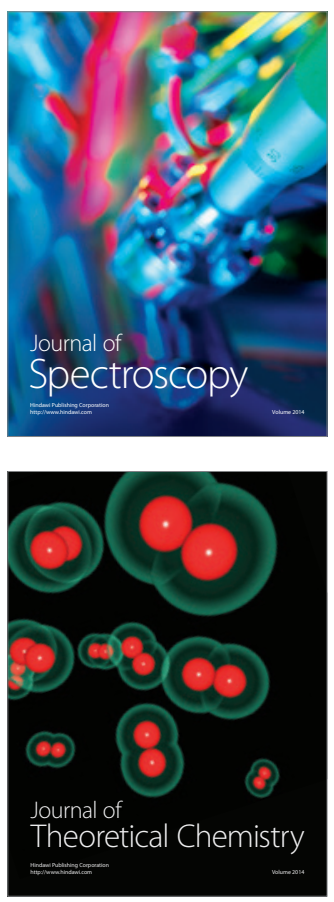
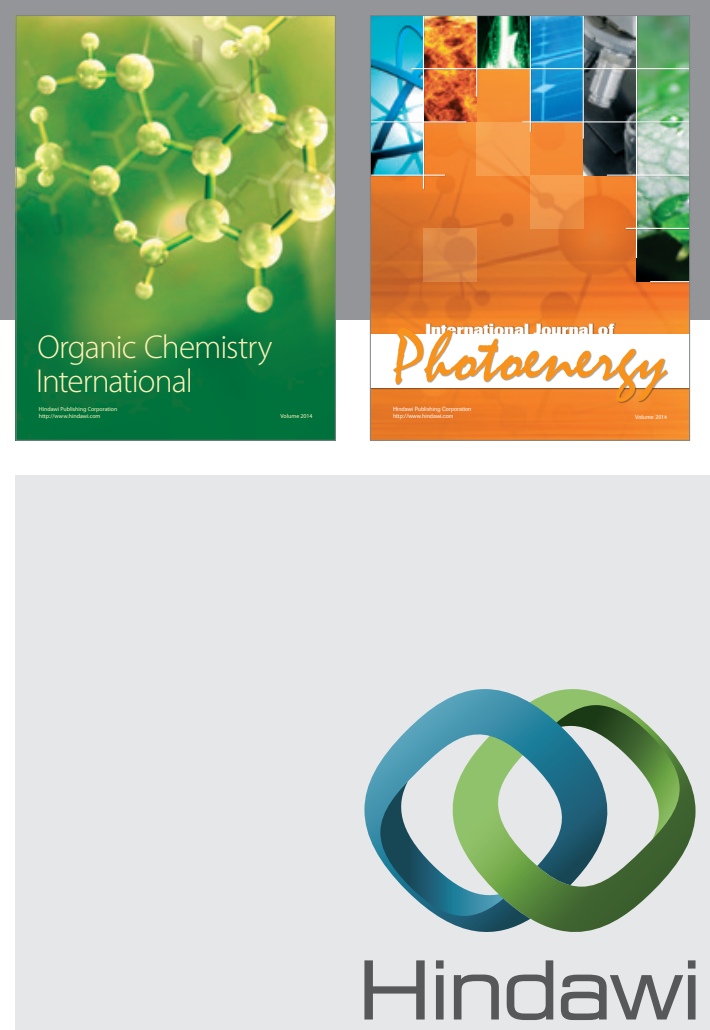

Submit your manuscripts at

http://www.hindawi.com
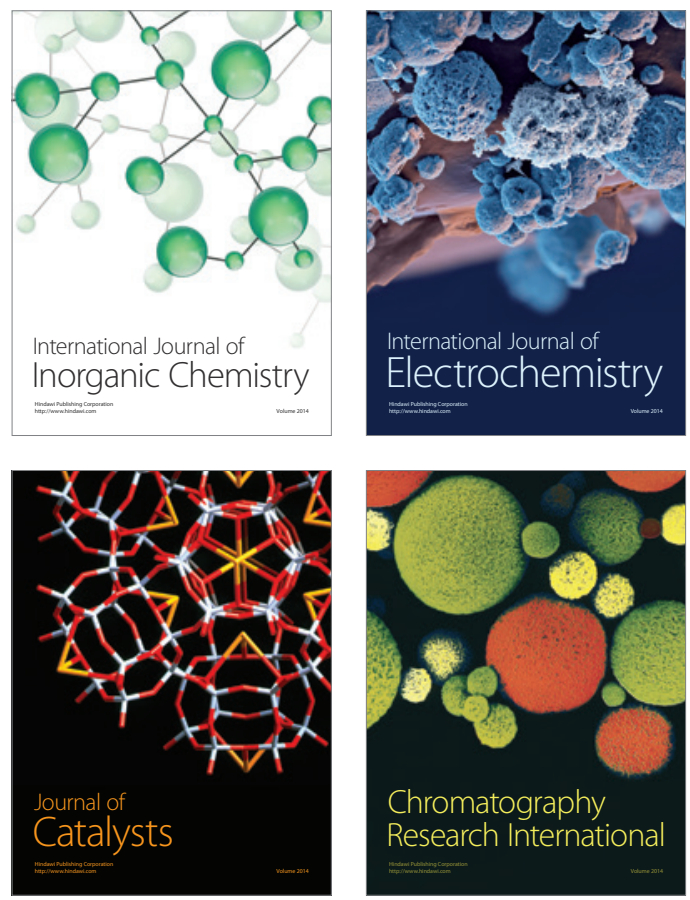
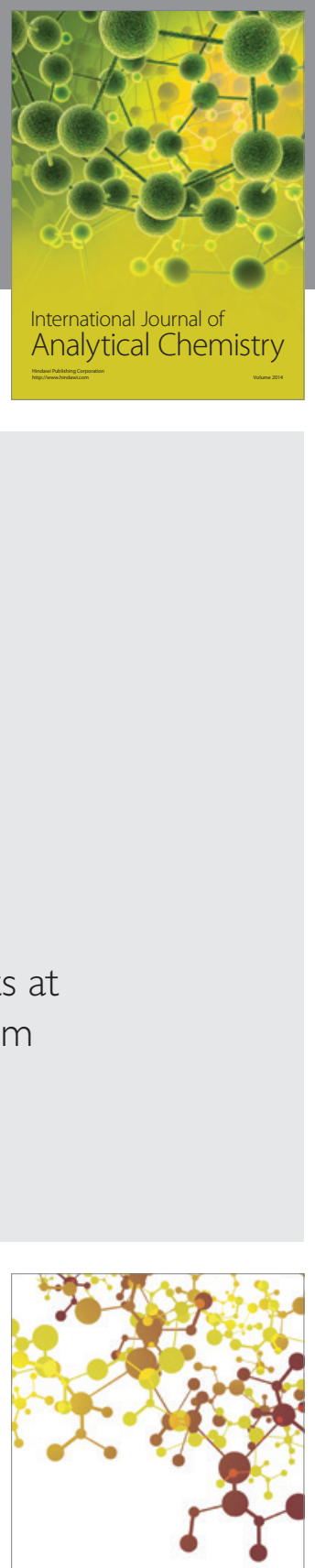

Journal of

Applied Chemistry
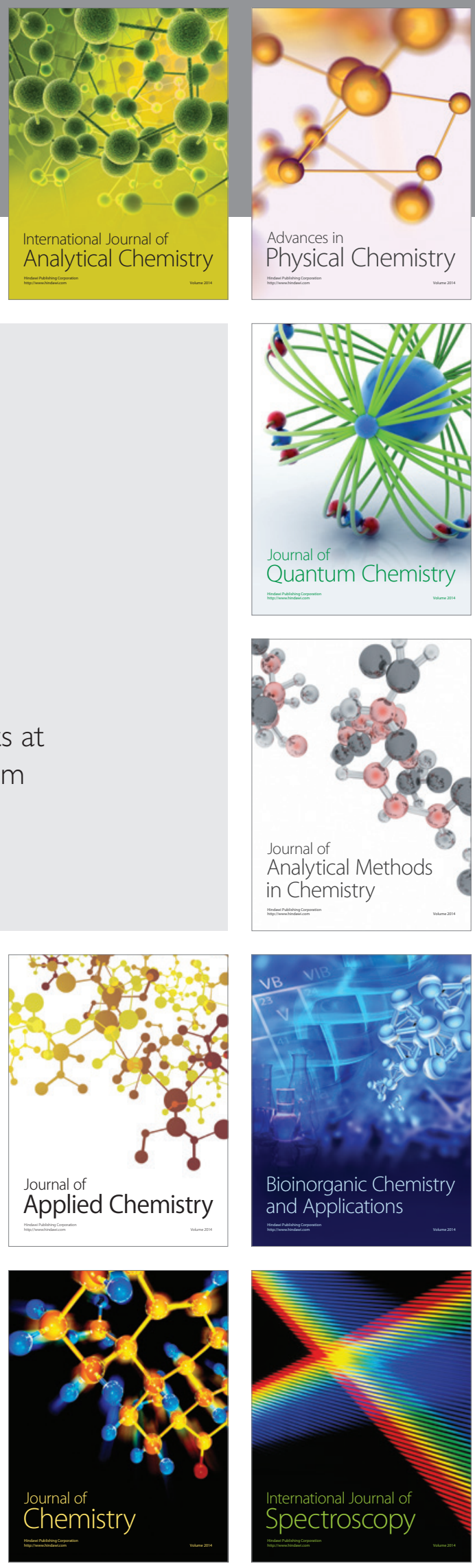